\title{
Allozyme and mtDNA variation in populations of the Daphnia pulex complex from both sides of the Rocky Mountains
}

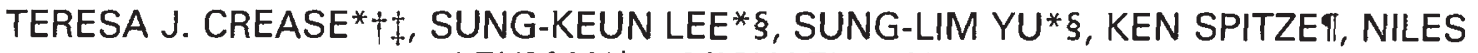 \\ LEHMAN\$ \& MICHAEL LYNCH\# \\ ‡Department of Zoology, University of Guelph, Guelph, Ontario, Canada N1G 2W1, §Division of Biological Sciences, \\ University of Missouri, Columbia, MO 65211, IDepartment of Biology, University of Miami, Coral Gables, FL \\ 33124-0421, \$Department of Biological Sciences, California State University, Long Beach, CA 90815, and \\ \#Department of Biology, University of Oregon, Eugene, OR 97403-1210, U.S.A.
}

Long-distance dispersal of diapausing eggs by migratory waterfowl is one factor thought to be responsible for the macrogeographical homogeneity of allozyme frequencies in species of the Daphnia pulex complex. If so, populations on either side of the Rocky Mountains are expected to be divergent because few major flyways cross them. To test this prediction, Daphnia populations from lakes and ponds across eastern Oregon were surveyed for mtDNA and allozyme variation. The data were analysed with previously collected data from populations in the midwest U.S. Phenetic analysis of the allozyme data clustered the populations into four discrete groups, which correspond to habitat: permanent lakes, ponds in the midwest, coastal and valley ponds in Oregon and sand dune ponds in Oregon. A recent taxonomic revision by Hebert suggests that these groups correspond to $D$. pulicaria, $D$. pulex, $D$. arenata and $D$. melanica, respectively. Cladistic analysis of mtDNA variation revealed the same groups except that mtDNA haplotypes from the $D$. pulex and $D$. pulicaria populations formed a single clade. All four species were significantly subdivided with respect to allozyme markers, but there were no clear differences between $D$. pulicaria populations on either side of the Rocky Mountains, suggesting that they are not a barrier to gene flow in this species. Whereas mtDNA differentiation among $D$. pulicaria populations was not significant, the pond-dwelling species, $D$. pulex and $D$. arenata, showed even greater differentiation for mtDNA than for allozymes. It is suggested that extinction/recolonization events occur more frequently in pond vs. lake habitats and have a greater impact on the subdivision of mtDNA variation because of the haploid, maternal inheritance of the mitochondrial genome.

Keywords: allozymes, Daphnia, geographical variation, mitochondrial DNA, population structure.

\section{Introduction}

Planktonic organisms that live in temporary freshwater habitats are generally thought to be capable of long-distance dispersal via desiccation-resistant diapausing eggs that disperse via agents such as the wind or highly vagile waterfowl. Even so, studies of both nuclear and mitochondrial variation have revealed large differences in gene frequencies among freshwater zooplankton populations in close proximity to one another (Crease et al., 1990);

*'The first three authors are co-first authors and are listed alphabetically.

†Correspondence. E-mail: tcrease@uoguelph.ca possibly the residual effect of founder events involving small numbers of propagules (Boileau et al., 1992). In some species, despite substantial subdivision at the level of individual populations, little additional differentiation has been observed among regional gene pools (Crease et al., 1990; Cerný \& Hebert, 1993; Hebert et al., 1993). Crease et al. (1990) argued that this pattern was observed among populations of the cladoceran Crustacean, Daphnia pulex, from the midwestern U.S. because of its postPleistocene northward expansion via colonization of newly available pond habitats by small numbers of diapausing eggs. An extensive survey of allozyme variation of $D$. pulex across Canada revealed a 
similar pattern: little macrogeographical differentiation of allozyme frequencies among regions within the western provinces or within the eastern provinces (Hebert et al., 1993). However, a distinct genetic discontinuity between east and west was observed, and Hebert et al. (1993) suggested that it was probably the result of the expansion of $D$. pulex from two separate glacial refugia.

If long-distance dispersal of $D$. pulex by waterfowl is responsible for genetic homogeneity on a macrogeographical scale, populations divergent from those in eastern North America might be expected to occur west of the Rocky Mountains as few major migratory flyways cross them. However, Hebert et al.'s (1993) results did not reveal any substantial differentiation in allele frequencies (pooled across populations within provinces) between British Columbia and the prairie provinces. In order to investigate patterns of macrogeographical differentiation further on an east-west axis, allozyme and mitochondrial DNA (mtDNA) diversity in populations of Daphnia located west of the American Rockies were surveyed, and compared with data from populations in the midwest U.S.

\section{Materials and methods}

\section{Daphnia collections}

Daphnia populations in Oregon were sampled between 1990 and 1992. Two lakes from the midwest U.S. - Lake Mendota, WI, and Gull Lake, MI were also sampled. Data from populations of $D$. pulex (Crease et al., 1990) located in Illinois were also included in the analysis. Collections were made from temporary pond habitats by dipnet and from permanent lakes by oblique tow from a boat. Animals were returned to the laboratory and maintained in culture for subsequent allozyme and mtDNA analysis.

\section{Allozyme analysis}

Four polymorphic enzyme systems were analysed by starch-gel electrophoresis according to the method described in Lynch (1983): Pgm (EC 5.4.2.2), Pgi (EC 5.3.1.9), Got (EC 2.6.1.1) and Pep (EC 3.4.11/13). Seven polymorphic loci were assayed on cellulose acetate gels according to the methods of Hebert \& Beaton (1989): Fum (EC 4.2.1.2), Mpi (EC 5.3.1.8), $L d h$ (EC 1.1.1.27), $M e$ (EC 1.1.1.40), $M d h$ (EC 1.1.1.37), Hex (EC 2.7.1.1) and Apk (EC 3.1.3.1). Nei's genetic distance (Nei, 1972) was calculated between all pairs of populations, and a dendrogram was constructed from the resulting matrix using the program $\mathrm{KITSCH}$ in the software package PHYLIP (Felsenstein, 1993). The degree of differentiation among populations within major groups (see Results) was calculated using Nei's (1987) gene diversity index.

\section{mtDNA analysis}

The methods described in Crease et al. (1989) were used to extract total DNA from Daphnia and to assay restriction site variability of mtDNA with the Southern transfer approach. The following 21 type II restriction enzymes were used: $A p a \mathrm{I}, A v a \mathrm{I}, B a m \mathrm{HI}$, BclI, BglII, BstEII, ClaI, DraI, EcoRI, EcoRV, HindIII, HpaI, MluI, NcoI, PstI, PvuII, SacI, StuI, $X b a \mathrm{I}, X h o \mathrm{I}$ and XmnI. Nylon membranes were probed with three ${ }^{32} \mathrm{P}$-labelled (Feinberg \& Vogelstein, 1983) $D$. pulex mtDNA fragments, and restriction sites were mapped as in Crease et al. (1989). Sequence divergence between pairs of mtDNA haplotypes was calculated by the maximum likelihood method of Nei \& Tajima (1983). The average number of substitutions per nucleotide between random pairs of mitochondria (mtDNA variation) within and between populations was calculated by the method of Lynch \& Crease (1990). Differentiation among populations was calculated using their $N$-statistic.

Cladistic analysis of the relationships among the mtDNA haplotypes was carried out using the computer program PAUP (Swofford, 1993). Bootstrap analysis was performed on a subset of the taxa after preliminary analyses identified major clades.

\section{Results}

\section{Allozyme variation}

Allele frequency data for individual populations are described in detail in K. Spitze et al. (unpublished data). The phenetic analysis of these data revealed the existence of four groups: populations in sand dune ponds, populations in temporary ponds in the Willamette Valley and along the Pacific coast, populations in permanent lakes and populations in temporary ponds in Illinois (Fig. 1). The Illinois populations have been identified as $D$. pulex on the basis of diagnostic allele frequencies (Crease et al., 1990). The near-fixation of the $F$ allele at $L d h$ in the lake populations suggests that they should be classified as D. pulicaria (Hebert et al., 1993). The other two groups most probably correspond to two new species recently described by Hebert (1995): $D$. 
melanica (dune populations) and $D$. arenata (valley populations).

Daphnia melanica was quite divergent from the other three groups as it possessed a unique allele (or one that was rare in other species) at Apk, Hex, Got and $P g i$ (Table 1). Animals in dune populations also possessed distinct melanic pigmentation in the dorsal carapace and represent the only known occurrence of melanic forms in temperate habitats (Hebert, 1995). In addition to the $F$ allele at $L d h, D$. pulicaria was characterized by the near-fixation of the $S$ allele at Hex. Two features characterized the $D$. arenata populations: the predominance of the $M$ allele at $\mathrm{Mpi}$ (which was also found very rarely in some $D$. pulicaria and $D$. pulex populations) and a high frequency of the Pgi-S allele.

$G$-statistics were calculated for each of the four groups identified by the phenetic analysis (Table 2). Mean values across all polymorphic loci within a group ranged from a high of 0.33 for $D$. arenata to a low of 0.15 for $D$. melanica. All estimates were significantly greater than zero. Although there was significant differentiation in allozyme frequencies among D. pulicaria populations overall, no distinction could

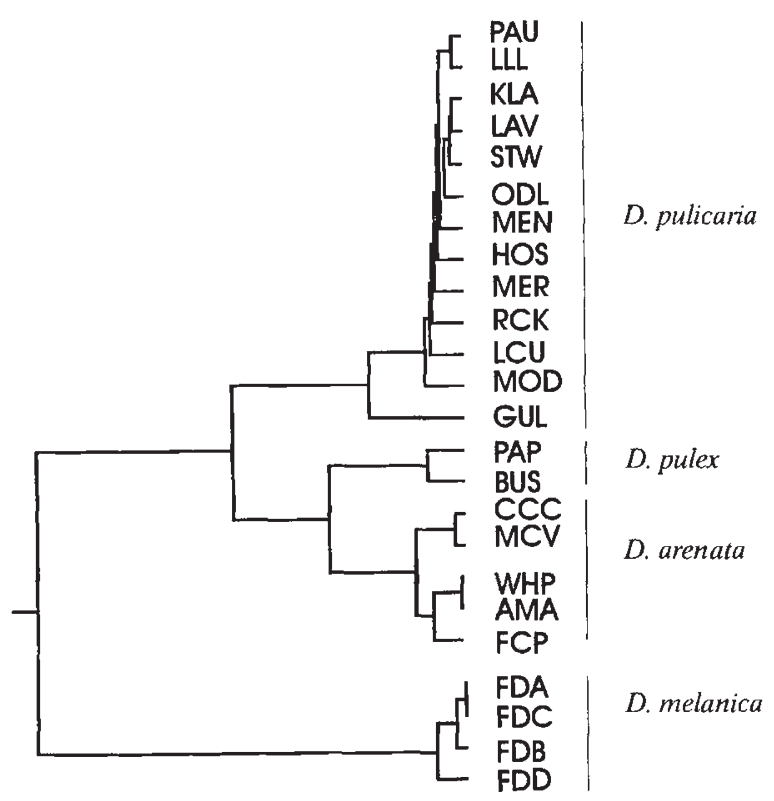

Fig. 1 Phenogram constructed from allozyme frequencies in populations of the Daphnia pulex group from Oregon and the midwest U.S. The midwest populations are MEN (Wisconsin), GUL (Michigan), PAP and BUS (Illinois). Two populations from each group (except $D$. melanica) were omitted from this analysis to maintain the number of taxa below 25 for computational purposes. Membership of the missing populations in the expected clades was confirmed in other analyses (data not shown). be made between populations from either side of the Rockies (Fig. 1).

\section{Phylogenetic analysis of mtDNA variation}

Mitochondrial restriction site variation was assayed in 12 Oregon populations: five of $D$. pulicaria, three of $D$. arenata and four of $D$. melanica. All but three (SCP, FDF and FDK) of these were also included in the allozyme survey. A sample from Gull Lake, MI was also analysed for mtDNA variation. The mtDNA haplotypes observed in cyclically parthenogenetic populations of $D$. pulex from Illinois (Crease et al., 1990) were included in all subsequent analyses, as was a single mtDNA haplotype (ONT) from a population of $D$. pulicaria from a lake in northern Ontario, Canada.

Twenty-nine distinct mtDNA haplotypes were found in the Oregon and Gull Lake populations. In general, Oregon haplotypes had limited distributions: only seven were found in more than one population (Table 3). A total of 123 restriction sites, equivalent to $738 \mathrm{bp}$ and 4.8 per cent of the mitochondrial genome, were recognized. Fifty-one of these sites were useful for cladistic analysis. On average, a mtDNA haplotype had 75 sites. Site data for the mtDNA haplotypes are available from the authors on request.

Cladistic analysis of the mtDNA haplotypes from Oregon and the midwest revealed four distinct clades (Fig. 2), which generally corresponded to the groups recognized by the allozyme analysis (Fig. 1). All but two haplotypes (OR11 and OR32) from $D$. melanica dune populations (Table 3 ) formed a clade that was quite divergent from all of the other groups. All of the haplotypes from $D$. arenata populations also clustered with one another. Contrary to expectations based on allozymes, mtDNA haplotypes from the Oregon (OR2-12) and midwest $D$. pulicaria (MI) populations clustered with haplotypes from Illinois (IL) D. pulex populations. There was very little phylogenetic structure in this clade; it consisted of a large polytomous group of haplotypes differing from one another by one or two autapomorphic restriction site differences. In contrast, the D. pulicaria isolate from northern Ontario (ONT) was quite divergent from this clade. The RCK population, which clustered with $D$. pulicaria in the allozyme analysis, contained haplotypes belonging to both the $D$. pulex/D. pulicaria clade (OR6, OR8 and OR9) and the $D$. arenata clade (OR7). However, OR7 was quite divergent from the other $D$. arenata types (Fig. 2) and even clustered with MI2 at the base of the $D$. pulex/D. pulicaria clade on a neigh- 
Table 1 Mean allele frequencies $( \pm S E)$ at 11 polymorphic allozyme loci in species of the Daphnia pulex complex from Oregon and the midwest U.S.

\begin{tabular}{|c|c|c|c|c|}
\hline & D. melanica & D. arenata & D. pulex & D. pulicaria \\
\hline$n$ & 4 & 7 & 4 & 15 \\
\hline \multicolumn{5}{|l|}{$P g m$} \\
\hline$F^{\prime}$ & $0.03(0.03)$ & - & - & - \\
\hline$F$ & - & $0.12(0.07)$ & $0.23(0.09)$ & $0.17(0.04)$ \\
\hline$M$ & $0.80(0.11)$ & $0.30(0.11)$ & $0.66(0.19)$ & $0.64(0.06)$ \\
\hline$M-$ & - & - & - & $0.02(0.01)$ \\
\hline$S$ & - & $0.58(0.14)$ & $0.11(0.10)$ & $0.13(0.05)$ \\
\hline$S^{\prime}$ & $0.17(0.10)$ & - & - & - \\
\hline$S-$ & - & - & - & $<0.01(<0.01)$ \\
\hline$S=$ & - & - & - & $0.03(0.02)$ \\
\hline$S_{\text {三 }}$ & - & - & - & $0.01(0.01)$ \\
\hline \multicolumn{5}{|l|}{$P g i$} \\
\hline$F+$ & - & - & - & $0.05(0.02)$ \\
\hline$F^{\prime}$ & - & $0.18(0.11)$ & - & - \\
\hline$F$ & $0.02(0.02)$ & - & $0.01(0.01)$ & $0.18(0.04)$ \\
\hline$M+$ & - & - & $<0.01(<0.01)$ & - \\
\hline$M$ & $0.01(0.01)$ & $0.18(0.10)$ & $0.95(0.02)$ & $0.64(0.06)$ \\
\hline$M-$ & - & - & $0.01(0.01)$ & - \\
\hline$S$ & - & $0.72(0.09)$ & $0.02(0.02)$ & $0.10(0.04)$ \\
\hline$S^{\prime}$ & - & - & - & $0.02(0.02)$ \\
\hline$S-$ & $0.97(0.03)$ & $0.10(0.06)$ & - & - \\
\hline \multicolumn{5}{|l|}{ Got } \\
\hline$F$ & $1.00(0.00)$ & - & - & $0.13(0.04)$ \\
\hline$M$ & - & $1.00(0.00)$ & $0.97(0.02)$ & $0.87(0.04)$ \\
\hline$S-$ & - & - & $0.03(0.02)$ & - \\
\hline \multicolumn{5}{|l|}{$P e p$} \\
\hline$F$ & - & ND & $0.01(0.01)$ & $<0.01(0.04)$ \\
\hline$M$ & $1.00(0.00)$ & ND & $0.85(0.07)$ & $1.00(0.00)$ \\
\hline$S$ & - & ND & $0.14(0.07)$ & - \\
\hline \multicolumn{5}{|l|}{ Fum } \\
\hline$M$ & - & - & $0.14(0.11)$ & $0.02(0.02)$ \\
\hline$S$ & $1.00(0.00)$ & $1.00(0.00)$ & $0.86(0.11)$ & $0.97(0.02)$ \\
\hline$S-$ & - & - & - & $0.01(0.01)$ \\
\hline \multicolumn{5}{|l|}{$M p i$} \\
\hline$F$ & - & $0.01(0.01)$ & - & - \\
\hline$M$ & - & $0.98(0.01)$ & $0.01(0.01)$ & $0.04(0.02)$ \\
\hline$S$ & $1.00(0.00)$ & $0.01(0.01)$ & $0.94(0.05)$ & $0.96(0.02)$ \\
\hline$S-$ & - & - & $0.05(0.05)$ & $<0.01(<0.01)$ \\
\hline \multicolumn{5}{|l|}{$L d h$} \\
\hline$F$ & $0.01(0.01)$ & - & - & $0.95(0.02)$ \\
\hline$S$ & $0.99(0.01)$ & $1.00(0.00)$ & $1.00(0.00)$ & $0.05(0.02)$ \\
\hline \multicolumn{5}{|l|}{$M e$} \\
\hline$F$ & - & - & - & $<0.01(<0.01)$ \\
\hline$M$ & $1.00(0.00)$ & $1.00(0.00)$ & $1.00(0.00)$ & $0.99(0.01)$ \\
\hline$S$ & - & - & - & $0.01(0.01)$ \\
\hline \multicolumn{5}{|l|}{$M d h$} \\
\hline$F$ & - & - & - & $<0.01(<0.01)$ \\
\hline $\begin{array}{c}M \\
\text { (contin }\end{array}$ & $\begin{array}{c}1.00(0.00) \\
\text { on next page })\end{array}$ & $1.00(0.00)$ & $1.00(0.00)$ & $1.00(0.00)$ \\
\hline
\end{tabular}

$n$, number of populations analysed. ND, no data. 
Table 1 Continued

\begin{tabular}{ccccc}
\hline & D. melanica & D. arenata & D. pulex & D. pulicaria \\
\hline Hex & & & & \\
$F$ & $0.98(0.02)$ & - & - & - \\
$M$ & - & $1.00(0.00)$ & $1.00(0.00)$ & $0.03(0.03)$ \\
$S$ & $0.02(0.02)$ & - & - & $0.97(0.03)$ \\
$A p k$ & & - & - & $0.01(0.01)$ \\
$F$ & $1.00(0.00)$ & $1.00(0.00)$ & $1.00(0.00)$ & $0.99(0.01)$ \\
$M$ & - & &
\end{tabular}

$n$, number of populations analysed. ND, no data.

bour-joining tree constructed from the matrix of sequence divergence values (data not shown). The 50 per cent majority-rule consensus tree generated in the bootstrap analysis of a subset of the haplotypes had a topology similar to this neighbourjoining tree (Fig. 3). There was bootstrap support for the distinction between the $D$. pulex $/ D$. pulicaria and the $D$. arenata clades, but support for the inclu- sion of OR7 in either clade was weak and its affiliation remains unclear.

Average sequence divergence between haplotypes within major clades was less than 1 per cent (Table 4 ). Only one isolate of 'eastern' D. pulicaria (ONT) was analysed, and average sequence divergence between this haplotype and the Oregon/Michigan $D$. pulicaria haplotypes was 2.9 per cent, a value similar

Table 2 MtDNA variation (average number of nucleotide substitutions between random mitochondria) within and between populations of the Daphnia pulex complex from Oregon and the midwest U.S., and fixation indices for mtDNA $(N$-statistic) and allozyme ( $G$-statistic) variation

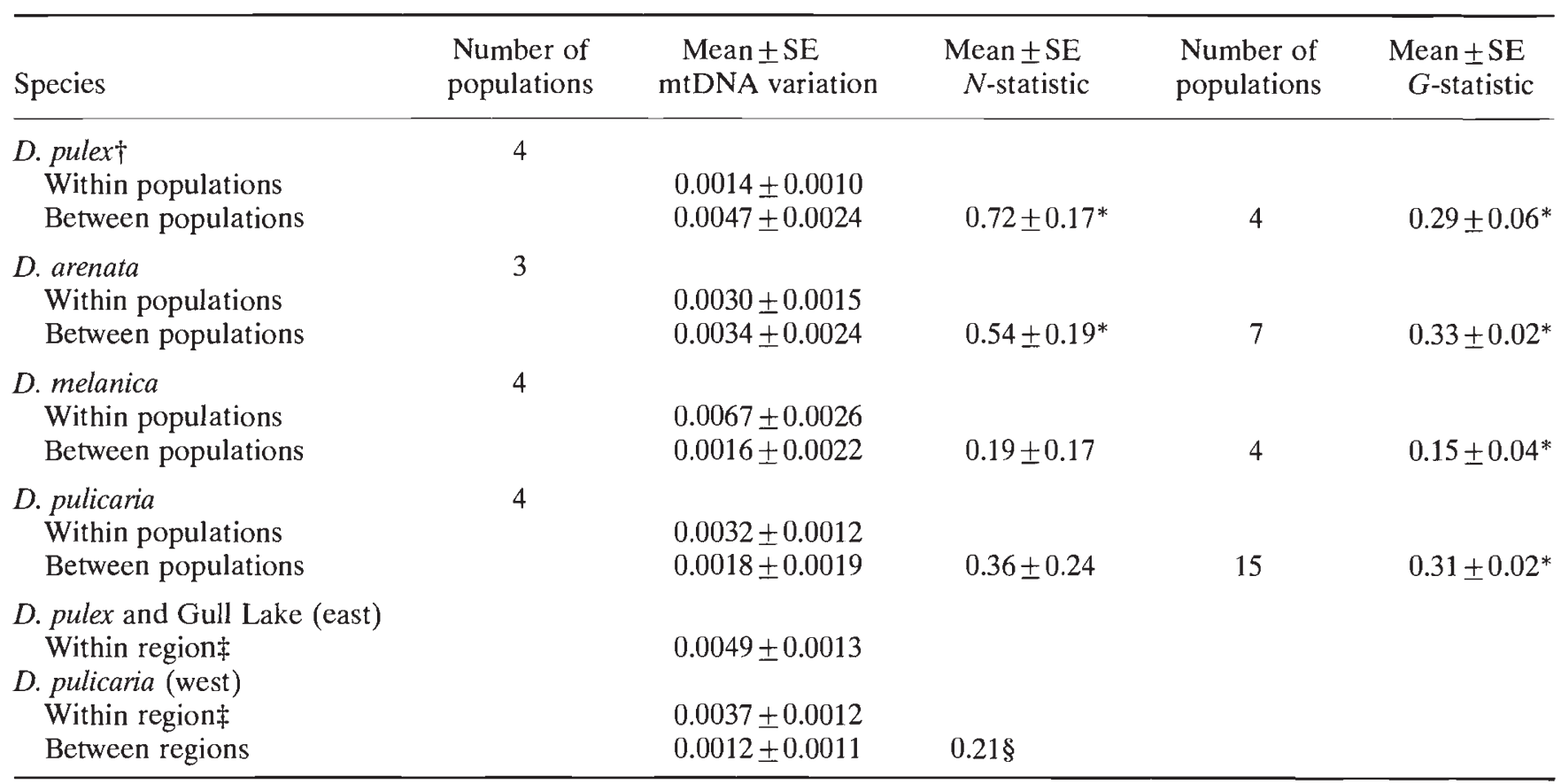

$\dagger$ Data from Crease et al. (1990).

$\ddagger$ Populations within each region were pooled to form one large population.

$\S$ Standard errors are not calculated when there are fewer than three populations (Lynch \& Crease, 1990).

${ }^{*} N_{\mathrm{ST}}$ or $G_{\mathrm{ST}}>0(P<0.01)$. 


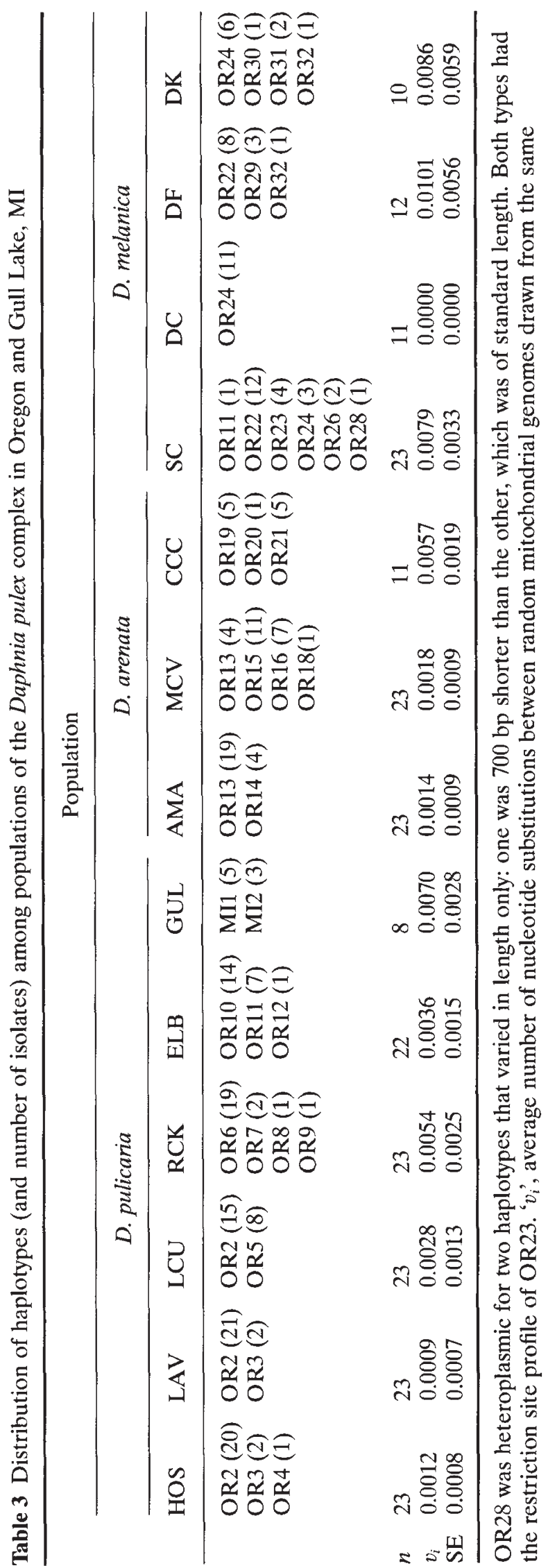

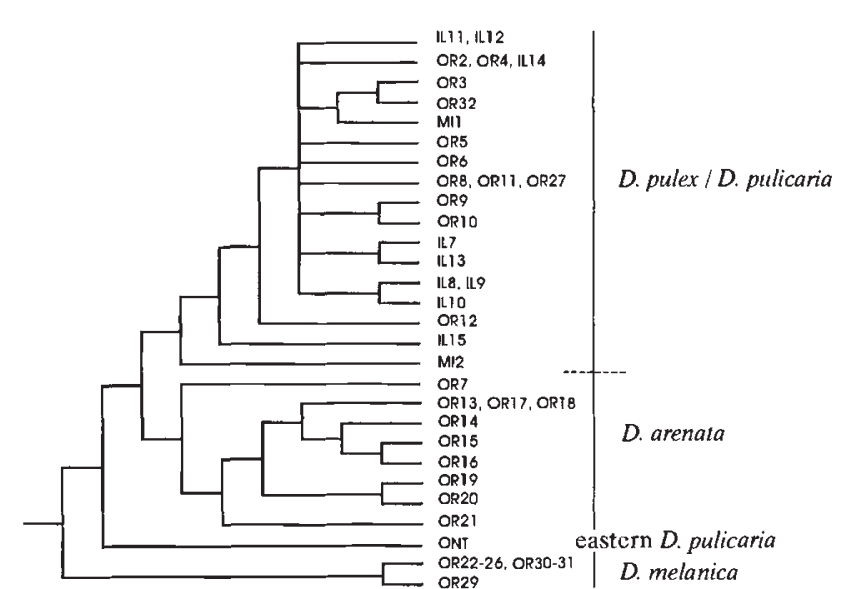

Fig. 2 Cladogram constructed from mtDNA haplotypes identified in populations of the Daphnia pulex complex from Oregon and the midwest U.S. The first two letters of each haplotype correspond to the state in which it was collected: IL, Illinois; OR, Oregon; MI, Michigan. ONT is an isolate of $D$. pulicaria from northern Ontario. The tree is based on 51 phylogenetically informative restriction sites and represents the strict consensus of 16 equally parsimonious trees of 91 steps and a consistency index of 0.56 . The only differences among these trees involved the arrangement of taxa within the $D$. pulex/D. pulicaria clade. Haplotypes in this clade from Illinois (IL) have been classified as $D$. pulex using diagnostic allozyme alleles. All other haplotypes in this clade have been classified as $D$. pulicaria.

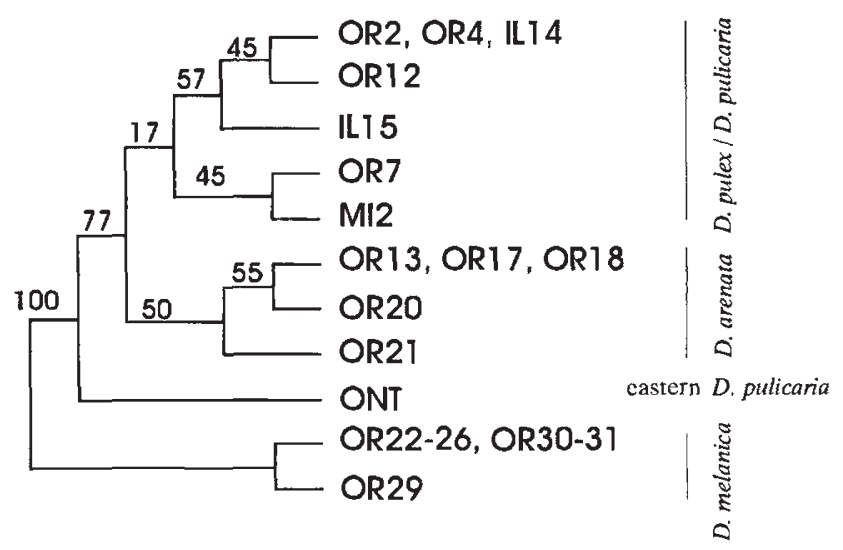

Fig. 3 The 50 per cent majority-rule consensus cladogram of relationships among mtDNA haplotypes representative of each of the major clades in Fig. 3. One thousand bootstrap replicates were generated for this analysis. The Daphnia melanica haplotypes were used as the outgroup. 
Table 4 Mean sequence divergence between mtDNA haplotypes $( \pm S D)$ within and between species of the Daphnia pulex complex from Oregon and the midwest U.S.

\begin{tabular}{|c|c|c|c|c|c|}
\hline & D. melanica & D. arenata & $\begin{array}{l}\text { D. pulicaria } \\
\text { (Ontario) }\end{array}$ & D. pulicaria & $\begin{array}{l}\text { D. pulex } \\
\text { (Illinois) }\end{array}$ \\
\hline D. melanica & $\begin{array}{c}0.0033 \\
(0.0014)\end{array}$ & $\begin{array}{c}0.0358 \\
(0.0044)\end{array}$ & $\begin{array}{c}0.0436 \\
(0.0023)\end{array}$ & $\begin{array}{c}0.0387 \\
(0.0028)\end{array}$ & $\begin{array}{c}0.0403 \\
(0.0026)\end{array}$ \\
\hline D. arenata & & $\begin{array}{c}0.0081 \\
(0.0046)\end{array}$ & $\begin{array}{c}0.0314 \\
(0.0023)\end{array}$ & $\begin{array}{c}0.0153 \\
(0.0028)\end{array}$ & $\begin{array}{c}0.0148 \\
(0.0028)\end{array}$ \\
\hline $\begin{array}{l}\text { D. pulicaria } \\
\text { (Ontario) }\end{array}$ & & & - & $\begin{array}{c}0.0287 \\
(0.0023)\end{array}$ & $\begin{array}{c}0.0277 \\
(0.0027)\end{array}$ \\
\hline D. pulicaria & & & & $\begin{array}{c}0.0085 \\
(0.0046)\end{array}$ & $\begin{array}{c}0.0076 \\
(0.0030)\end{array}$ \\
\hline $\begin{array}{l}\text { D. pulex } \\
\text { (Illinois) }\end{array}$ & & & & & $\begin{array}{c}0.0065 \\
(0.0021)\end{array}$ \\
\hline
\end{tabular}

These values were obtained by averaging all pairwise estimates of sequence divergence between haplotypes within or between the species under consideration.

to the mean sequence divergence between ONT and those from $D$. pulex (2.8 per cent). Daphnia melanica was the most divergent from the other three groups, as was the case with allozymes. Average sequence divergence between haplotypes from $D$. melanica and the other species ranged from 3.6 per cent to 4.4 per cent (Table 4).

\section{Population genetic analysis of mtDNA variation}

Mean mtDNA nucleotide diversity within and among populations was calculated separately for each species. Mean intrapopulation variation ranged from 0.0014 in the Illinois $D$. pulex populations to 0.0067 in the $D$. melanica populations. Mean interpopulation diversity was highest in the $D$. pulex populations (0.0047) and lowest in the $D$. melanica populations (0.0016; Table 2). There was no significant subdivision of mtDNA diversity among $D$. pulicaria populations, including the one from Gull Lake, MI (Table 2). The three mountain populations (HOS, LAV and LCU) were all dominated by the same haplotype (OR2) and the haplotypes present in RCK (OR6-9) and Gull Lake (MI1-2) were closely related to this haplotype and/or rare (Fig. 2 and Table 3). Subdivision among $D$. melanica populations was also not significant, but the $D$. arenata populations were highly subdivided (Table 2). Only one haplotype was shared among the three populations (Table 3), and intraspecific sequence divergence in this species was high (Table 4). A similar result was obtained for $D$. pulex in Illinois, which had little haplotype overlap among populations (Crease et al., 1990) and a similar value of mean intraspecific sequence divergence (Table 4).

Although the allozyme analysis suggested that midwest $D$. pulex and Oregon $D$. pulicaria are highly divergent at nuclear loci, subdivision between the two groups with respect to mtDNA diversity $\left(N_{\mathrm{ST}}=0.21\right)$ was lower than subdivision among the D. pulicaria populations themselves $\left(N_{\mathrm{Sr}}=0.36 \pm\right.$ $0.24)$. In the case of the pond-inhabiting species $(D$. pulex and $D$. arenata), there was more subdivision with respect to mitochondrial genes than there was with respect to nuclear genes (allozymes).

\section{Discussion}

Although the Oregon populations surveyed in this study resembled one another morphologically, genetic analyses segregated them into discrete groups. Comparison with allozyme data from Illinois populations (Crease et al., 1990; fig. 1) suggested that none of the Oregon or midwest lake populations could be classified as $D$. pulex. Thus, it was not possible to estimate differentiation on either side of the Rocky Mountains for this species. However, populations of $D$. pulicaria from both sides of the American Rockies were sampled, and little divergence between east and west was observed. This result is concordant with that of Cerný \& Hebert (1993), who observed no genetic discontinuity in 
allozyme frequencies between populations of $D$. pulicaria sampled from permanent lakes in several states on either side of the Rocky Mountains.

All four species identified in the present study showed similar levels of intraspecific population subdivision at allozyme loci (Table 2). However, there were marked differences in levels of subdivision with respect to mtDNA. In general, the species inhabiting temporary habitats, $D$. pulex and $D$. arenata, showed a higher degree of population structure than did the lake species, $D$. pulicaria. This may be related to the relative time over which individual habitats exist. Although ponds may exist in the same place for substantial periods of time, their 'lifespan' is likely to be much shorter than that of lakes, which could persist for hundreds or perhaps thousands of years. Thus, the increased frequency of extinction/recolonization events among ponds (relative to lakes), and the fact that such populations are likely to be founded by small numbers of individuals may contribute to differences in the level of differentiation among populations living in the two types of habitats. That this difference had a much greater impact on mtDNA than on allozyme differentiation (Table 2) is concordant with the fact that the effective population size for mitochondrial loci is only one-quarter that for allozyme loci because of the haploid, maternal inheritance of mtDNA. Interestingly, the species inhabiting the most ephemeral habitats, $D$. melanica, showed the least amount of population subdivision. However, the ponds sampled were in close geographical proximity and they generally lacked variation, which may be a direct consequence of their extreme ephemerality (K. Spitze et al., unpublished results).

Despite the interspecific differentiation identified in this survey, mtDNA and allozyme markers generally characteristic of one species sometimes occurred in low frequency in populations of another species. Assuming that these markers really are diagnostic, there are two obvious explanations for such observations: that two species occasionally inhabit the same body of water without interbreeding, or that there has been some introgression of markers between species via hybridization. To evaluate these possibilities, individuals from anomalous populations should be analysed for both mtDNA and allozyme variation in order to identify associations between markers that would indicate a lack of gene flow between the species. Such information is not available for the samples analysed in this study. However, more detailed work on dune populations has led $\mathrm{N}$. Lehman and D. Straughan (unpublished observations) to conclude that there is a relatively rare melanic ' $D$. pulicaria-like' entity coexisting with $D$. melanica, and that there is little or no gene flow between them. This would explain the occurrence of D. pulicaria mtDNA and allozymes in some dune populations. Whether or not this will also be the situation for the other cases of 'marker leakage' is not currently known. However, there is evidence that some hybridization does occur between species in this area. One population near the Oregon coast was found to contain a single multilocus allozyme genotype that was most probably generated by hybridization between $D$. melanica and $D$. arenata (M. Lynch, personal observation). This 'clone' had D. arenata mtDNA.

The most dramatic case of 'marker leakage' in the present study was the similarity between mtDNA haplotypes found in D. pulex and in D. pulicaria, despite their clear allozymic differentiation (Figs 1 and 2). The production of obligately parthenogenetic $F_{1}$ clones via hybridization between these two species has been well documented (Crease et al., 1989, 1990; Hebert et al., 1993). However, there is little evidence of introgression of genetic markers beyond the $F_{1}$. Crease et al. (1989) first reported $D$. pulicaria isolates with $D$. pulex mtDNA from a pond on Peche Island in the Detroit River. They suggested that this may be unusual, as $D$. pulicaria from the river could come into contact with ponddwelling $D$. pulex during flooding of the island. However, a broader survey of $D$. pulicaria, using analysis of a PCR-amplified portion of the ND4 and ND5 genes (Dufresne, 1995), indicated that D. pulicaria populations with $D$. pulex mtDNA occur in other locations in the U.S. (North Dakota, Wyoming). Dufresne's study also revealed the existence of at least three other mtDNA lineages in $D$. pulicaria. Their distributions were largely disjunct: in the Arctic, in western North America and in eastern North America, and they probably differentiated in separate glacial refugia during the Pleistocene period (Dufresne, 1995). The isolate of $D$. pulicaria from Ontario (ONT) belongs to the 'eastern' lineage.

Despite the mosaic of mtDNA lineages in $D$. pulicaria, the species remains cohesive allozymically across North America (Cerný \& Hebert, 1993; the present study), and shows clear differentiation from D. pulex in regions in which they co-occur (Hebert et al., 1993). The maintenance of nuclear differentiation, despite the introgression of mtDNA from a closely related species, has been observed in other organisms (Lehman et al., 1991 and references therein). However, in D. pulicaria, such introgression occurs over a broad geographical area, and intro- 
gressed populations are interspersed with those possessing mtDNA that is not $D$. pulex-like. Indeed, the $D$. pulex-like mtDNA lineage is the most widespread of any found in D. pulicaria, and the Rocky Mountains have clearly not presented a barrier to its dispersal.

Hybridization is not unique to the $D$. pulex group. It has been well documented in the $D$. longispina group in Europe and North America (Taylor \& Hebert, 1992; Schwenk, 1993) and in the D. carinata complex in Australia (Hebert \& Wilson, 1994). However, this intermixing does not often seem to progress beyond the initial $F_{1}$ generation. Indeed, backcross and $F_{2}$ individuals are usually rare in cases where they have been sought (Taylor \& Hebert, 1992; Hebert \& Wilson, 1994), although Taylor \& Hebert (1992) did find evidence for introgression of several allozymes from $D$. rosea to $D$. galeata mendota in lakes from the midwest U.S., and backcrosses have been generated in the laboratory between hybrid females $(D$. pulex $\times D$. pulicaria $)$ and D. pulex males (L. Nass, unpublished thesis).

Lehman et al. (1995) have argued that the genus Daphnia may best be thought of as a limited group of fluid genetic complexes rather than discrete species. The ubiquity of hybridization among species complexes that have been studied genetically is concordant with this view. However, despite the hybridization, the genetic structure of all of these Daphnia species complexes is not continuous; there are genetic discontinuities (diagnostic allozymes and mtDNA) that are consistent with the existence of entities between which gene flow is restricted. Thus, although the systematics of the genus may at times be confused by the occurrence of hybrids and the lack of substantial morphological differentiation, the genetic analyses suggest that it is somewhat premature to abandon the notion of species in this group.

The importance of shifts in habitat use to the speciation process in Daphnia has long been appreciated (Lynch, 1985) and, indeed, clear habitat associations were evident in the present study. Daphnia melanica was only found in sand dune ponds. Melanism in Daphnia is believed to provide protection from UV radiation (Hebert \& Emery, 1990). Dune ponds are extremely clear and quite shallow, so that zooplankton populations are likely to experience intense exposure to UV radiation. A similar situation exists in many Arctic ponds where melanism in Daphnia is common (Weider \& Hebert, 1987).

Daphnia pulicaria and D. pulex are both broadly distributed across North America, but they tend to occupy different habitats; the former generally occurs in lakes containing planktivorous fish, whereas the latter is almost exclusively restricted to ponds lacking fish (Hebert, 1995). Notably, D. pulex was not detected in this survey of Oregon habitats; instead, $D$. arenata seemed to inhabit ponds in which $D$. pulex would normally occur. However, unlike $D$. pulex, the distribution of $D$. arenata is apparently restricted to a small geographical area in western Oregon (Hebert, 1995). This situation is not unique in the genus as several narrowly distributed Daphnia species with closely related, widely distributed congeners are found in Oregon (Hebert, 1995). Moreover, the occurrence of narrowly distributed species endemic to western Oregon has also been observed in several small vertebrates including salamanders (Good \& Wake, 1992) and ranid frogs (Green et al., 1996). The fragmentation of species ranges into southern refugia during Pleistocene glacial advances has been suggested as stimulating speciation (Green et al., 1996). The high frequency of endemism among diverse taxa associated with western Oregon, which is located just south of the maximum extent of the Cordillera ice sheet, suggests that this region remained isolated during much of the Pleistocene glacial period.

\section{Acknowledgements}

We thank Lara Bowman, Lara Bull, Stan Dodson, Gary Henderson, Paul Jarrell, John Korte and Tanya Leatham for help in obtaining samples. Lara Bowman, Igor Chaplik, Gary Henderson, Tanya Leatham and Charles Oh assisted in allozyme data collection. Financial support was provided by a Summer Award from Natural Sciences and Engineering and a General Research Support Award from the Research Council of the University of Miami, and National Science Foundation grants DEB 92-20634 to K.S. and BSR 86-00487 to M.L.

\section{References}

BOILEAU, M. G., HEBERT, P. D. N. AND SCHWARTZ, S. S. 1992. Non-equilibrium gene frequency divergence: persistent founder effects in natural populations. J. Evol. Biol., 5, 25-39.

ČERNÝ, M. AND HEBERT, P. D. N. 1993. Genetic diversity and breeding system variation in Daphnia pulicaria from North American lakes. Heredity, 71, 497-507.

CREASE, T. J., STANTON, D. J. AND HEBERT, P. D. N. 1989. Polyphyletic origins of asexuality in Daphnia pulex. II. Mitochondrial-DNA variation. Evolution, 43, 10161026.

CREASE, T. J., LYNCH, M. AND SPITZE, K. 1990. Hierarchical analysis of population genetic variation in mitochon-

(C) The Genetical Society of Great Britain, Heredity, 79, 242-251. 
drial and nuclear genes of Daphnia pulex. Mol. Biol. Evol., 7, 444- 458.

DUfresne, F. 1995. Genetic Relationship among Arctic Daphnia: Implications for the Origins and Evolutionary Significance of Polyploidy. PhD Thesis, University of Guelph, Guelph, ON.

FEINBERG, A. P. AND VOGElstein, B. 1983. A technique for radiolabelling DNA restriction endonuclease fragments to high specific activity. Analyt. Biochem., 132, 6-13.

FEISENSTEIN, J. 1993. PHYLIP (Phylogeny Inference Package). Version 3.5c. Department of Genetics, University of Washington, Seattle, WA.

GOOD, D. A. AND WAKE, D. B. 1992. Geographic variation and speciation in the torrent salamanders of the genus Rhyacotriton (Caudata: Rhyacotritonidae). Univ. Calif. Publ. Zool., 126, 1-91.

GREEN, D. M., SHARBEL, T. F., KEARSLEY, J. AND KAISER, H. 1996. Postglacial range fluctuation, genetic subdivision and speciation in the western North American spotted frog complex. Evolution, 50, 374-390.

HeBert, P. D. N. 1995. The Daphnia of North America: An Illustrated Fauna. CD-ROM. University of Guelph, Guelph, ON.

HEBERT, P. D. N. AND BEATON, M. J. 1989. Methodologies for Allozyme Analysis using Cellulose Acetate Electrophoresis. Helena Laboratories, Beaumont, TX.

HEBERT, P. D. N. AND EMERY, C. J. 1990. The adaptive significance of cuticular pigmentation in Daphnia. Funct. Ecol., 4, 703-710.

HEBERT, P. D. N. AND WiLSON, C. C. 1994. Provincialism in plankton: endemism and allopatric speciation in Australian Daphnia. Evolution, 48, 1333-1349.

HEBERT, P. D. N., SCHWARTZ, S. S., WARD, R. D. AND FINSTON, T. L. 1993. Macrogeographic patterns of breeding system diversity in the Daphnia pulex group. I.
Breeding systems of Canadian populations. Heredity, 70, 148-161.

LEHMAN, N., EISENHAWER, A., HANSEN, K., MECH, L. D., PETERSON, R. O., GOGAN, P. J. P. AND WAYNE, R. K. 1991. Introgression of coyote mitochondrial DNA into sympatric North American gray wolf populations. Evolution, 45, 104-119.

LEHMAN, N., PFRENDER, M. E., MORIN, P. A., CREASE, T. J. AND LYNCH, M. 1995. A hierarchical molecular phylogeny within the genus Daphnia. Mol. Phylog. Evol., 4, 395- 407.

LYNCH, M. 1983. The ecological genetics of Daphnia pulex. Evolution, 37, 358-374.

LYNCH, M. 1985. Speciation in the Cladocera. Verh. Int. Verein. Limnol., 22, 3116-3123.

LYNCH, M. AND CREASE, T. J. 1990. The analysis of population survey data on DNA sequence variation. $\mathrm{Mol}$. Biol. Evol., 74, 377-394.

NEI, M. 1972. Genetic distance between populations. Am. Nat., 106, 288-292.

NEI, M. 1987. Molecular Evolutionary Genetics. Columbia University Press, New York.

NEI, M. AND TAJIMA, F. 1983. Maximum likelihood estimation of the number of nucleotide substitutions from restriction site data. Genetics, 105, 207-217.

sCHWENK, K. 1993. Interspecific hybridization in Daphnia: distinction and origin of hybrid matrilines. Mol. Biol. Evol., 10, 1289-1302.

SWOFFORD, D. L. 1993. PAUP (Phylogenetic Analysis Using Parsimony) Version 3.1.1. Illinois Natural History Survey, Champaign, IL.

TAYLOR, D. J. AND HEBERT, P. D. N. 1992. Daphnia galeata mendotae as a cryptic species complex with interspecific hybrids. Limnol. Oceanogr., 37, 658-665.

WEIDER, L. J. AND HEBERT, P. D. N. 1987. Microgeographic genetic heterogeneity of melanic Daphnia pulex at a low-arctic site. Heredity, 58, 391-399. 